\title{
Bagaço de cana-de-açúcar tratado com hidróxido de sódio
}

\section{Aureliano José Vieira Pires ${ }^{1}$, Ricardo Andrade Reis ${ }^{2}$, Gleidson Giordano Pinto de Carvalho ${ }^{3}$, Gustavo Rezende Siqueira ${ }^{4}$, Thiago Fernandes Bernardes ${ }^{5}$}

\footnotetext{
${ }^{1}$ Departamento de Tecnologia Rural e Animal, UESB, Itapetinga, BA.

2 Departamento de Zootecnia, UNESP, Jaboticabal, SP.

${ }^{3}$ Mestrando em Zootecnia, UFV, Viçosa, MG.

${ }^{4}$ Mestrando em Zootecnia, UNESP, Jaboticabal, SP.

${ }^{5}$ Doutorando em Zootecnia, UNESP, Jaboticabal, SP.
}

RESUMO - O experimento foi conduzido com o objetivo de avaliar a composição química e a digestibilidade in vitro da matéria seca (MS) do bagaço de cana-de-açúcar contendo $60 \%$ de MS submetido a doses crescentes de hidróxido de sódio ( $\mathrm{NaOH}$ ) (0; 2,5; 5 e 7,5\% de uma solução 2:1 de água: $\mathrm{NaOH}$ na MS) em diferentes períodos de tratamento (1, 3, 5 e 7 dias). Foram utilizados baldes plásticos com capacidade de $10 \mathrm{~L}$, mantidos em uma câmara climática à temperatura constante de $25^{\circ} \mathrm{C}$. Não foi verificado efeito dos tratamentos (dose de $\mathrm{NaOH}$ e dias de tratamento) sobre os teores de $\mathrm{PB}$, que apresentaram valor médio de 1,6\%. A MS aumentou com os dias de tratamento, não sendo observadas alterações para essa variável em relação às doses crescentes de $\mathrm{NaOH}$. Foi observada redução das frações de FDN, FDA, celulose (CEL), hemicelulose (HEM) e lignina (LIG) A digestibilidade in vitro da matéria seca (DIVMS) e o teor de sódio aumentaram quando o bagaço de cana foi submetido a doses crescentes de $\mathrm{NaOH}$, mas não foi observado efeito do período de tratamento sobre essas variáveis. O valor nutritivo do bagaço de cana é melhorado com a adição de $\mathrm{NaOH}$, comprovado pela redução nos constituintes da parede celular e pelo aumento na DIVMS.

Palavras-chave: digestibilidade, parede celular, resíduo

\section{Sugarcane bagasse treated with sodium hydroxide}

\begin{abstract}
The experiment was conducted with the objective of evaluating chemical composition and in vitro dry matter digestibility of sugar-cane bagasse containing $60 \%$ dry matter submited to increasing sodium hydroxide concentrations $(0,2.5,5$, and $7.5 \% \mathrm{NaOH}$ on a dry matter basis). $\mathrm{NaOH}$ was applied as a $2: 1$ water: $\mathrm{NaOH}$ solution, over different treatment times $\left(1,3,5\right.$, and 7 days). Plastic pails with $10 \mathrm{~L}$ capacity were utilized and stocked in climatic chamber at $25^{\circ} \mathrm{C}$ constant temperature. The experimental treatments had no effect on the crude protein content of the sugar cane bagasse which averaged $1.6 \% \mathrm{CP}$. The dry matter content of the bagasse increased over of the days of treatment, without any effect of the $\mathrm{NaOH}$ solution concentration. Mean values for the bagasse neutral detergent fiber, acid detergent fiber, cellulose, hemicellulose and lignin contents declined in response to NAOH solution concentration. $\mathrm{NaOH}$ treatment improved the in vitro dry matter digestibility (IVDMD) and sodium content of the bagasse. Time of treatment had no effect on these variables. The treatment of sugar cane bagasse with the $\mathrm{NaOH}$ solution improved its nutritive value in terms of its reduced cell wall constituents and increased IVDMD.
\end{abstract}

Key Words: cell wall, digestibility, residue

\section{Introdução}

O bagaço de cana de cana-de-açúcar tem sido utilizado como fonte alternativa na suplementação animal no período de escassez de forragens. Porém, uma vez que, como outros alimentos fibrosos, é constituído de celulose, hemicelulose e lignina, sua utilização tem sido minimizada, por ser considerado volumoso de baixa qualidade.

Segundo Ferreira et al. (2000), o teor de fibra tem sido utilizado como índice negativo de qualidade, uma vez que representa a fração menos digestível dos alimentos. A fração fibrosa dilui a energia do alimento e reduz o consumo voluntário, pelo efeito do enchimento ruminal e pela saturação da capacidade de ruminação do animal.

Alguns tratamentos são realizados com o intuito de melhorar a utilização do bagaço de cana-de-açúcar e de outros subprodutos vegetais, que podem ser físicos e/ou químicos. Entre os tratamentos físicos, destacam-se a moagem e o tratamento térmico, e, entre os químicos, a uréia, a amônia anidra e o hidróxido de sódio $(\mathrm{NaOH})$, produtos 
alcalinos que normalmente promovem redução da FDN, podendo influenciar positivamente o consumo de MS do alimento.

O tratamento químico de alimentos volumosos tem crescido bastante nos últimos anos e várias pesquisas têm evidenciado que o valor nutritivo de diferentes volumosos pode ser melhorado com a utilização de produtos químicos (Cândido et al., 1999; Reis et al., 2001; Santos et al., 2004), entre eles, o tratamento de volumosos com amônia anidra, uréia e/ou $\mathrm{NaOH}$ (Souza et al., 2002).

Segundo Al-Masri \& Guenther (1999), o tratamento químico com $\mathrm{NaOH}$ tem sido utilizado para quebrar o composto lignocelulósico das forragens e aumentar proporcionalmente seus componentes nutritivos. Conforme Pereira Filho et al. (2003), as palhadas, os restolhos de culturas, o bagaço de cana-de-açúcar e os fenos de gramíneas de baixo valor nutritivo estão entre os alimentos mais submetidos ao tratamento químico com $\mathrm{NaOH}$, que, normalmente, proporciona ganhos de 20 a 50\% na DIMS.

Santos et al. (2004) relataram que a associação de $\mathrm{NaOH}$ mais uréia no tratamento de resíduo de lixadeira de algodão melhoraram a degradabilidade da MS e da FDN, melhorando seu valor nutritivo.

Realizou-se este experimento com o objetivo de avaliar o efeito de doses de $\mathrm{NaOH}$ sobre a composição química e a digestibilidade in vitro da matéria seca (DIVMS) do bagaço de cana-de-açúcar em diferentes períodos de tratamento.

\section{Material e Métodos}

O experimento foi conduzido no setor de Forragicultura da FCAV/UNESP, Campus de Jaboticabal, SP. Foi utilizado o bagaço de cana-de-açúcar proveniente da indústria de álcool.

Utilizou-se o esquema de parcelas subdivididas, considerando-se parcelas as quatro doses $(0 ; 2,5 ; 5$ e 7,5\% base da MS) de uma solução 2:1 (peso:peso) água:hidróxido de sódio $(\mathrm{NaOH})$ e, como subparcelas, os períodos de tratamento (1, 3, 5 e 7 dias), com três repetições, totalizando 48 unidades amostrais.

O bagaço utilizado estava triturado e não necessitou ser picado. O material apresentou $60 \%$ de MS e, mesmo contendo alta umidade, não evidenciava sinais de fungos.

$\mathrm{O}$ bagaço foi acondicionado em baldes plásticos com capacidade de $10 \mathrm{~L}$ e permaneceu em câmara climática à temperatura constante de $25^{\circ} \mathrm{C}$. A solução de $\mathrm{NaOH}$ foi adicionada ao bagaço nas respectivas dosagens de $0 ; 2,5$; 5 e 7,5\% na MS por meio de um pulverizador, sendo adicionada ao bagaço aos poucos, com homogeneização constante sobre uma lona. Após a homogeneização, o material foi armazenado nos baldes correspondentes a cada repetição, os quais permaneceram abertos nos respectivos períodos de tratamento (1, 3, 5 e 7 dias). Amostras foram coletadas, pré-secas em estufa (a $65^{\circ} \mathrm{C}$ por 72 horas), processadas em moinho tipo Willey e armazenadas para posteriores análises de MS, nitrogênio total (NT), FDN, FDA, celulose, hemicelulose, lignina e digestibilidade in vitro da matéria seca (DIVMS), conforme procedimentos descritos por Silva \& Queiroz (2002).

Os dados foram analizados por meio de regressão, utilizando-se o programa SAEG versão 8.0 (UFV, 1998).

\section{Resultados e Discussão}

Não foi observado efeito $(\mathrm{P}>0,05)$ da interação doses de $\mathrm{NaOH} \times$ dias de tratamento para nenhuma das variáveis estudadas. Verificou-se efeito $(\mathrm{P}<0,05)$ dos dias de tratamento sobre o teor de MS, que apresentou aumento (Figura 1) pelo fato de o bagaço ficar armazenado conforme os dias de tratamento em uma câmara climática com temperatura constante de $25^{\circ} \mathrm{C}$, o que fez com que perdesse umidade com o passar dos dias. Não foi observado efeito $(\mathrm{P}>0,05)$ para essa variável em função das doses de $\mathrm{NaOH}$.

Não houve efeito $(\mathrm{P}>0,05)$ das doses de $\mathrm{NaOH}$ e dos dias de tratamento sobre o teor de PB, calculado pelo teor de NT multiplicado por 6,25, registrando-se valor médio de PB de 1,59\%, que pode ser considerado comum, visto que não foi adicionada fonte externa de nitrogênio

Também não houve efeito $(\mathrm{P}>0,05)$ dos dias de tratamento sobre a parede celular e seus constituintes, porém, verificou-se efeito significativo $(\mathrm{P}<0,05)$ das doses de $\mathrm{NaOH}$,

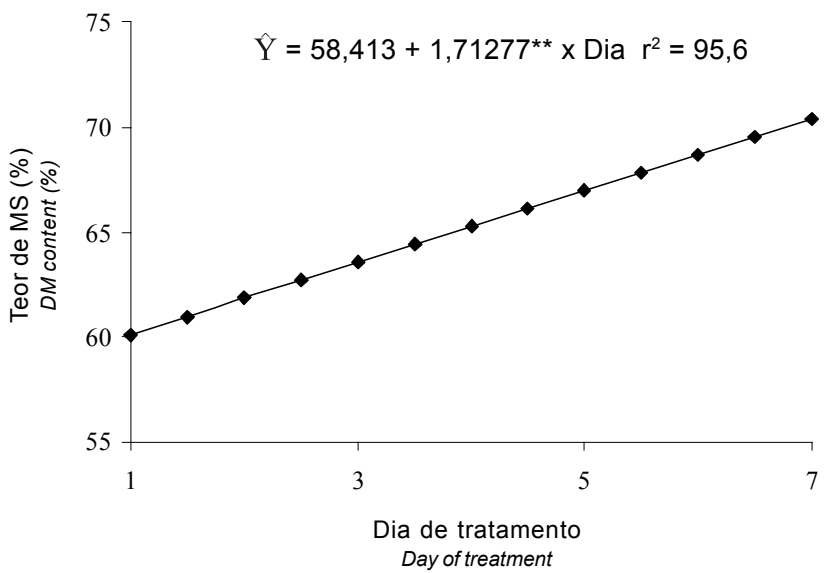

Figura 1 - Efeito dos dias de tratamento com hidróxido de sódio $(\mathrm{NaOH})$ sobre o teor de MS do bagaço de cana-deaçúcar.

Figure 1 - $\quad D M$ content of sugarcane bagasse as a function of sodium hydroxide $(\mathrm{NaOH})$ days of treatment. 
ocorrendo redução nos teores de FDN, FDA, celulose (Figura 2), lignina e hemicelulose (Figura 3).

Ao avaliarem resíduo de lixadeira de algodão submetido a tratamentos físicos e químicos, Santos et al. (2004) encontraram valores de 91,$51 ; 90,17 ; 86,23 ; 87,85$ e $82,89 \%$ de FDA, respectivamente, para os tratamentos controle (sem tratamento), pressão e vapor, $\mathrm{NaOH}$, uréia, e $\mathrm{NaOH}$ mais uréia. Segundo os autores, a combinação de tratamentos pode ser uma alternativa para melhorar o valor nutritivo de resíduos e subprodutos agroindustriais.

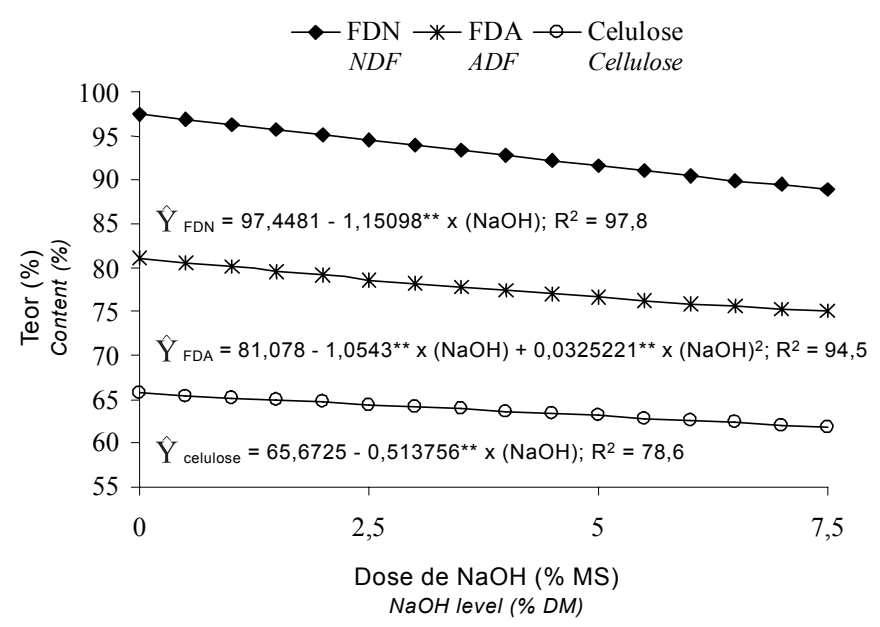

Figura 2 - Teores de FDN, FDA e celulose do bagaço de canade-açúcar submetido a doses crescentes de hidróxido de sódio $(\mathrm{NaOH})$.

Figure 2 - NDF, ADF and cellulose content of sugarcane bagasse submitted to increasing levels of sodium hydroxide $(\mathrm{NaOH})$.

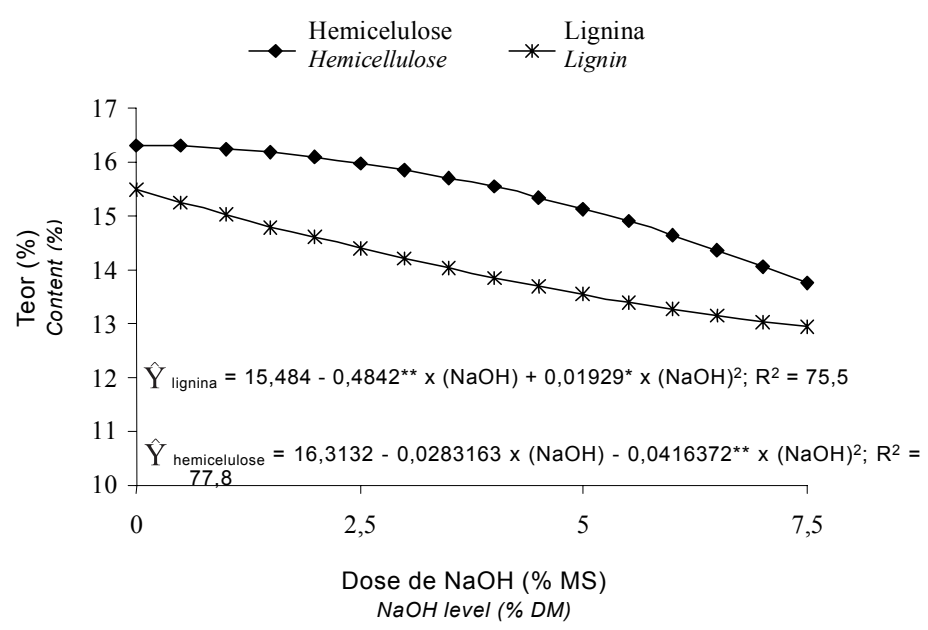

Figura 3 - Teores de hemicelulose e lignina do bagaço de canade-açúcar submetido a doses crescentes de hidróxido de sódio $(\mathrm{NaOH})$.

Figure 3 - Hemicellulose and lignin contents of sugarcane bagasse submitted to increasing levels of sodium hydroxide $(\mathrm{NaOH})$.
A redução na FDN observada neste estudo resultou da solubilização parcial dos constituintes da parede celular, pois o efeito de produtos alcalinos sobre volumosos de baixa qualidade normalmente ocorre pela solubilização parcial da hemicelulose e pela expansão da celulose, o que facilita o ataque dos microrganismos do rúmen à parede celular (Van Soest, 1994). Semelhantemente, Reis et al. (1990) observaram decréscimo nos teores de FDN (81,0 para 70,5\%) para o feno de Brachiaria decumbens não-tratado ou tratado com amônia anidra ( $3,0 \%$ da MS), respectivamente, $o$ que corresponde à redução de $12,96 \%$.

Pires et al. (2004) avaliaram o tratamento do bagaço de cana-de-açúcar com amônia anidra e/ou, sulfeto de sódio e constataram que a amônia anidra ( $4 \%$ na MS) melhorou a degradabilidade da MS, da FDN e da FDA, enquanto o sulfeto de sódio ( $2,5 \%$ na MS) não foi eficiente no tratamento do bagaço de cana-de-açúcar, mesmo quando associado à amônia anidra $\left(2,5 \% \mathrm{de} \mathrm{Na}_{2} \mathrm{~S}+4 \% \mathrm{de} \mathrm{NH}_{3}\right.$ da $\left.\mathrm{MS}\right)$.

A redução da hemicelulose é comum em gramíneas ou resíduos e subprodutos de gramíneas tratados com produtos alcalinos, como resultado de sua solubilização parcial.

Houve efeito quadrático crescente $(\mathrm{P}<0,05)$ das doses de $\mathrm{NaOH}$ (Figura 4) sobre a DIVMS. O aumento na DIVMS de materiais tratados com produtos alcalinos tem sido realatado na literatura (Pires et al., 1999; Sarmento et al., 1999), como resultado da solubilização parcial da hemicelulose e da expansão da celulose, o que facilita o ataque de microrganismos à parede celular.

Manzano et al. (2000) encontraram valores de 32,4; 48,7 e $62,4 \%$ para DIVMS do bagaço de cana-de-açúcar sem tratamento, com $2 \%$ de $\mathrm{Na}_{2} \mathrm{~S}+3 \%$ de $\mathrm{NaOH}$ e $4 \%$ de $\mathrm{Na}_{2} \mathrm{~S}$ $+4 \%$ de $\mathrm{NaOH}$, respectivamente. Embora os autores tenham utilizado uma fonte sulfurosa associada ao $\mathrm{NaOH}$, tudo indica que o $\mathrm{NaOH}$ exerceu influência sobre o bagaço, melhorando sua digestibilidade. Os aumentos na DIVMS de volumosos tratados com produtos alcalinos normalmente estão relacionados ao aumento do consumo e do desempenho de animais alimentados com esses volumosos, que podem, às vezes, apresentar resultados de desempenho semelhantes em comparação a dietas de melhor qualidade.

Segundo Neto \& Ferreira (1984), citados por Martin (1997), a DIVMS do bagaço de cana-de-açúcar aumentou gradativamente, com valores de 25,$9 ; 46,6$ e $77,0 \%$ para os tratamentos com 3, 6 e $14 \%$ de $\mathrm{NaOH}$.

D'arce \& Haddad (1989) estudaram a utilização do bagaço de cana-de-açúcar tratado com $\mathrm{NaOH}$ (3,6\% da MS) na terminação de bovinos de corte em confinamento, divididos ao acaso em dois grupos: Tratamento $\mathrm{A}$ - dieta com $60 \%$ de bagaço tratado $+5 \%$ de cana integral $+35 \%$ de 


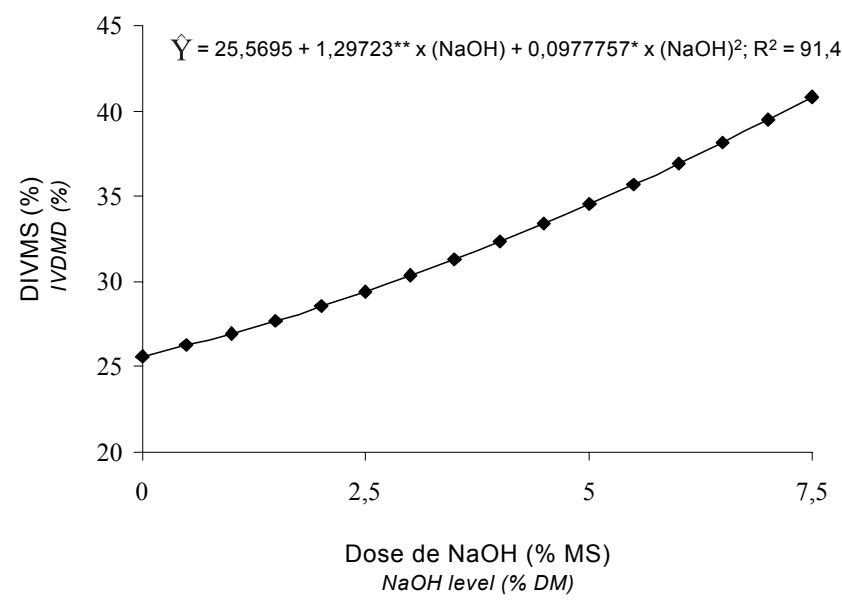

Figura 4 - Digestibilidade in vitro da matéria seca (DIVMS) do bagaço de cana-de-açúcar submetido a doses crescentes de hidróxido de sódio $(\mathrm{NaOH})$.

Figure 4 - Dry matter in vitro digestibility (IVDMD) of sugarcane bagasse submitted to increasing levels of sodium hydroxide $(\mathrm{NaOH})$.

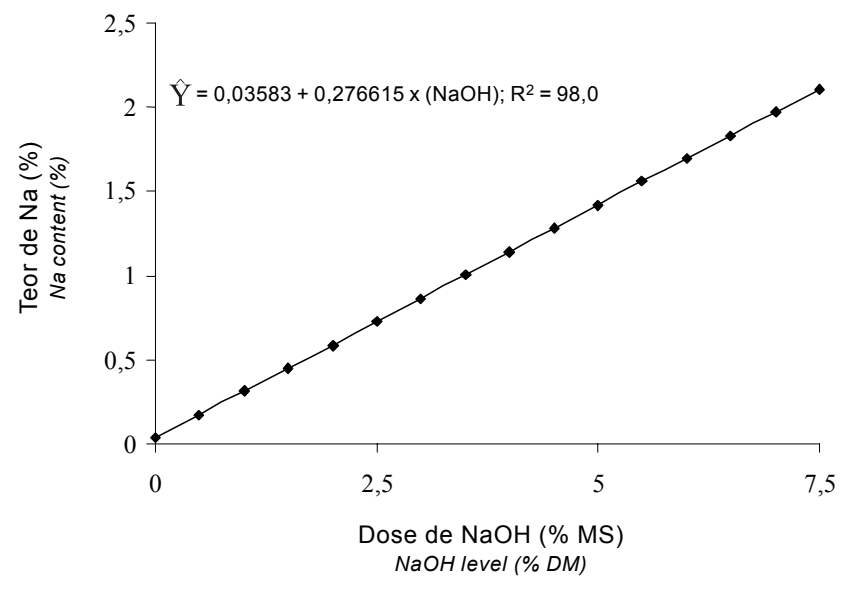

Figura 5 - Teor de sódio $(\mathrm{Na})$ do bagaço de cana-de-açúcar submetido a doses crescentes de hidróxido de sódio $(\mathrm{NaOH})$.

Figure 5 - Sodium ( $\mathrm{Na}$ ) content of sugarcane bagasse submitted to increasing levels of sodium hydroxide $(\mathrm{NaOH})$.

concentrado à base de milho, cama de frango e farelo de algodão; e Tratamento B - dieta com $65 \%$ de cana integral $+35 \%$ do mesmo concentrado. Os autores concluíram que não houve diferença entre os tratamentos quanto ao ganho médio de peso, ao consumo médio diário e à conversão alimentar e sugeriram a utilização do bagaço de cana tratado com $\mathrm{NaOH}$ como volumoso em dietas de terminação, desde que verificada sua viabilidade econômica.

O teor de sódio ( $\mathrm{Na}$ ) no bagaço (Figura 5) aumentou linearmente $(\mathrm{P}<0,05)$ com o aumento das doses de $\mathrm{NaOH}$, provavelmente pelo fato de o hidróxido apresentar significativo teor de $\mathrm{Na}$. A determinação do teor de $\mathrm{Na}$ no bagaço tratado é importante para ajustar a quantidade de $\mathrm{NaCl}$ a ser adicionada à mistura mineral suficiente para atender às exigências dos animais, uma vez que elevados teores de $\mathrm{Na}$ nas dietas podem provocar a redução do consumo da mistura e, conseqüentemente, diminuir a ingestão de macro e microminerais.

\section{Conclusões}

O bagaço de cana-de-açúcar tratado com hidróxido de sódio apresenta melhor valor nutritivo, sendo, portanto, uma alternativa para utilização como volumoso na alimentação de ruminantes.

\section{Literatura Citada}

AL-MASRI, M.R.; GUENTHER, K.D. Changes in digestibility and cell-wall constituents of some agricultural by-products and urea treatments. Radiation Physics and Chemistry, v.55, n.3, p.324-329, 1999.

CÂNDIDO, M.J.D.; NEIVA, J.N.M.; PIMENTEL, J.C.M. et al. Avaliação do valor nutritivo do bagaço de cana-de-açúcar amonizado com uréia. Revista Brasileira de Zootecnia, v.28, n.5, p.928-935, 1999.

D'ARCE, R.D.; HADDAD, C.M. Bagaço de cana tratado com hidróxido de sódio na terminação de bovinos em confinamento. In: REUNIÃO ANUAL DA SOCIEDADE BRASILERA DE ZOOTECNIA, 26., 1989, Porto Alegre. Anais... Porto Alegre: Sociedade Brasileira de Zootecnia, 1989. p.155.

FERREIRA, M.A.; SANTOS, D.C.; LIRA, M.A. et al. Associação da palma forrageira (Opuntia fícus indica Mill) com diferentes fontes de fibra na alimentação de vacas $5 / 8$ Holandês/Zebu em lactação. Revista Brasileira de Zootecnia, v.29, n.7, p.21282134, 2000.

MANZANO, R.P.; FUKUSHIMA, R.S.; GOMES, J.D.F. et al Digestibilidade do bagaço de cana-de-açúcar tratado com reagentes químicos e pressão de vapor. Revista Brasileira de Zootecnia, v.29, n.4, p.1196-1204, 2000.

MARTIN, L.C.T. Bovinos: volumosos suplementares. São Paulo: Nobel, 1997. 143p.

PIRES, A.J.V.; GARCIA, R.; CECON, P.R. et al. Amonização da quirera de milho com alta umidade. Revista Brasileira de Zootecnia, v.28, n.6, p.1186-1193, 1999.

PIRES, A.J.V.; GARCIA, R.; VALADARES FILHO, S.C. et al. Degradabilidade do bagaço de cana-de-açúcar tratado com amônia anidra e, ou, sulfeto de sódio. Revista Brasileira de Zootecnia, v.33, n.4, p.1071-1077, 2004.

REIS, R.A.; GARCIA, R.; SILVA, D.J. et al. Efeitos da aplicação de amônia anidra sobre a digestibilidade do feno de capim-brachiaria (Bracharia decumbens Stapf). Revista Brasileira de Zootecnia, v.19, n.3, p.201-208, 1990.

REIS, R.A.; RODRIGUES, R.L.A.; RESENDE, K.T. et al. Avaliação de fontes de amônia para o tratamento de fenos de gramíneas tropicais. 1. constituintes da parede celular, poder tampão e atividade ureática. Revista Brasileira de Zootecnia, v.30, n.3, p.674-681, 2001.

ROSA, B.; REIS, R.A.; RESENDE, K.T. et al. Valor nutritivo do feno de Brachiaria decumbens Stapf cv. Basilisk submetido a tratamento com amônia anidra ou uréia. Revista Brasileira de Zootecnia, v.27, n.4, p.815-822, 1998.

ROSA, B.; SOUZA, H.; RODRIGUES, K.F. Composição química do feno de Brachiaria brizantha cv. Marandu tratado com diferentes 
proporções de uréia e de água. Ciência Animal Brasileira, v.1, n.2, p.107-113, 2000.

SANTOS, J.; CASTRO, A.L.A.; PAIVA, P.C.A. et al. Efeito dos tratamentos físicos e químicos no resíduo de lixadeira do algodão. Ciência Agrotecnologia, v.28, n.4, p.919-923, 2004.

SARMENTO, P.; GARCIA, R.; PIRES, A.J.V. et al. Tratamento do bagaço de cana-de-açúcar com uréia. Revista Brasileira de Zootecnia, v.28, n.6, p.1203-1208, 1999.

SILVA, D.J.; QUEIROZ, A.C. Análise de alimentos (métodos químicos e biológicos). Viçosa, MG: Universidade Federal de Viçosa, 2002. 235p.

SOUZA, A.L.; GARCIA, R.; PEREIRA, O.G. et al. Valor nutritivo da casca de café tratada com amônia anidra. Revista Ceres, v.26, n.286, p.669-681, 2002.
UNIVERSIDADE FEDERAL DE VIÇOSA - UFV. Sistema de análises estatísticas e genéticas - SAEG. Versão 8.0. Viçosa, MG: 1998. 150p. (Manual do usuário).

Van SOEST, P.J. Nutritional ecology of the ruminant. 2.ed. Ithaca: Cornell University Press, 1994. 476p.

Recebido: $14 / 06 / 05$ Aprovado: $18 / 11 / 05$ 